\title{
A MODEL OF FAMILY AND CAREER RECONCILIATION
}

\author{
Ilona Tandzegolskienè \\ Elena Trepulè \\ Aušra Rutkienė \\ Giedrè Tamoliūnè \\ Vaida Jurgilè \\ Vytautas Magnus University, Lithuania
}

\begin{abstract}
The article focuses at these elements of family, work and career reconciliation which are relevant for seeking harmony and satisfaction in family and work settings. Presented theme refers to the analysis of work-family or family-work conflict, causes for role conflicts, facilitation strategies, conception of dual and individual career within a family, internal and external factors which influence start-up of conflicts and reconciliation strategies. This article presents results of data, collected during conduction of narrative interviews with young parents (both mother and father), semi-structured interviews with employers, focus group with career guide/human resources specialists and quantitative research with young families. The aim of research was to determine the needs and opportunities of young families who seek to balance family and career by highlighting influence of work activities. Research results identicated reconciliation for young families and career, possibilities for facilitation that is closely linked to dual and single career design couples, trends for career development, aware ness of parent hood and changing roles.
\end{abstract}

Keywords: career, conflict, family model, reconciliation, work activities.

\section{Introduction}

Overview of the literature which analyzes opportunities of young families to combine parenthood and career refers to many relevant themes, namely, work and family conflict or family and work conflict, the role of personality and the role conflict, relationships between work and family lives, work and family stressors, work and family social support, dual-earner partners, single-earners partners, career satisfaction, employing such concepts as enrichment, employee values, positive spillover, enhancement and facilitation (Grenhaus \& Powell, 2006; Michel et al., 2009; Carlson et al., 2000; Elloy \& Fand, 2003; Wayne et al., 2004; Thurairajah, 2013;Cesnauskas \& Lazauskaite-Zabielske, 2014). Work 
Ilona Tandzegolskienè, Elena Trepulè, Aušra Rutkienè, Giedrè Tamoliūnè, Vaida Jurgilè. A Model of Family and Career Reconciliation

and family or family and work conflicts appear when the needs of work and family do not correlate with the needs of family and work. The nature of such conflict contains negative consequences for all - an employee, his/her family and organization he/she belongs to. Outlasting conflict causes stress, depression, as well as increases sickness rate or decreases self-satisfaction of accomplished work, or even family life. Simultaneously, an organization is affected by inadequate employees' involvement in the implemented activities, increased intension to change working place, decrease of quality of the achieved results (Cesnauskas \& Lazauskaite-Zabielske, 2014). Therefore, executives and administration of diverse organizations attempt to decrease work and family conflict by the different means creating flexible work schedules, supporting maternity/paternity leave or child care services (Moen, 2003; Kempe \& Otonkorpi-Lehtoranta, 2006; Vuga \& Juvan, 2013; Cesnauskas \& LazauskaiteZabielske, 2014). Referring to the role theory, it might be indicated that each role has specific expectations and needs which ignorance would definitely cause certain conflicts within the roles (Frone et al., 2003). The role theory "has provided the broad theoretical umbrella for much of the work-family/familywork conflict literature. Role theory implies that work and family roles result from the expectations of others, and what is believed to be appropriate behaviour for a particular position (subordinate, coworker, spouse, father) (Michel et al., 2009: 200). It is highlighted that the conflict and the role performance tension experienced by a person in particular domain, in this case, it is work, usually is transferred to another domain, and in this case, it is family (Michel et al., 2009; Cesnauskas \& Lazauskaite-Zabielske, 2014). Work and family or family and work reconciliation by considering the needs of family members, role balance and commitment levels lead towards ability to transfer possessed knowledge and experience from one activity field (family) to another one (work), as well as to determine relevant and sensible career goals or highlight dominant family values and solid distribution of father's and mother's roles. Here the two concepts might be distinguished - family and parenthood. Family concept, in this case, is used in the different articles as the unit covering several components - being a couple, maintaining a common household, nurturing and educating children. This is relevant for making mutual decisions when family deals with conflicts or certain situations influencing its wealth and being related to the need to maintain good family relations and balance. Meanwhile, the concept of parenthood is highlighted more when role distribution within a family is presented, as well as solid search for compromises and balance between personal needs and opportunities, and career decisions.

Research problem. Analysis of family and work contexts refers to the research on work-family and family-work disquision, diverse roles ${ }^{6}$ influence on individual professional work, existing difficulties of double caree within a 
family. Yet, the research is missing which focuses on the analysis of family raising young children and searching for life and career balance. The reference is made to those families where couples together combine work and family models, analize own presence in a couple as family representative, as well as a parent who has certain responsibilities and at the same time seeks for family, work and career reconciliation.

The object of the research - family and career reconciliation.

The goal of the research - to determine the needs and opportunities of young families who seek to balance family and career by highlighting influence of work activities.

The tasks of the research:

1. To distinguish the main elements which are relevant for balancing the needs and opportunities of young family referring to the perspective of conflicts' analysis;

2. To develop model of family needs and opportunities reconciliation distinguishing the reconciliation aspects of career, work activities and family.

Methodology. The methods employed in this study are based on scientific literature analysis in the given topic of the research. The research has revealed that the dynamics of managing career and family responsibilities are mostly discussed focusing on the three angles that are based on the respective theories: conflict theory, facilitation theory and role theory. Article was based on experiences from Lithuania young families, employers, career guides' and human resource (HR) specialists'.

\section{Components relevant for validation of theoretical model: conflict perspective and facilitation}

Scientific literature survey revealed the three major strains that interact in the process of individuals managing their work and family responsibilities: they experience conflict when trying to meet the quirements of their work-place and family; the experience of both faculties - family and work not only generate conflict but also facilitation - being a good professional adds skills for successful family life and vice versa - being a good mother/father adds skills and qualities for a professional role at work; the different roles which are undertaken by individuals (mother or father) in their family and professional lives.

There are different theories that are being used to analyze the relationship of work and family. The most dominant is a conflict theory (Parasuraman \& Greenhouse, 2002; Greenhaus \& Powell, 2006). Due to the fact that time and human energy resources are limited, the conflict is inevitable (Hill, 2005). According to Coser (1974) concept, family and work are greedy institutions, 
Ilona Tandzegolskienè, Elena Trepulè, Aušra Rutkienè, Giedré Tamoliūnè, Vaida Jurgilè. A Model of Family and Career Reconciliation

seeking for unconditional and undivided loyalty from individuals. Working parents are facing conflicts in different situations, e.g., a working parent has to work late, so may miss his/her son's sports game or performance. If he/she is not able to stay late at work because of his/her child's game, the parent may feel like he/she is letting down his/her employer. Carlson et al. (2002) considered three different forms of wor-family conflict: (a) time-based conflict, (b) strain-based conflict and (c) behaviour-based conflict. "Time-based conflict may occup when time devoted to one role makes it difficult to participate in another role, strainbased conflict suggests that strain experienced in one role intrudes into and interferes with participation in another role, and behaviour-based conflict occurs when specific behaviour required in one role are incompatible with behavioural expectation in another role" (Carlson et al., 2000: 250). And this three forms have two directions: conflict directly to work interfering with family (WIF) and conflict directly to family interfering with work (FIW). Together these three conflicts forms and too direction are combined six dimension of conflict outcome: (a) time-based WIF, (b) time-based FIW, (c) strain-based WIF, (d) strain-based FIW, (e) behaviour-based WIF, and (f) behaviour-based FIW. Following work and family conflict presented in the literature as the dominant construct, three models can be mentioned (Michel et al., 2009: 201/202):

1. A parsimonious stressor and involvement model. The model conceptualizes work and family conflict or family and work conflict as mediating components between job stressors, job involvement, family stressors and family involvement, and outcomes of job distress, family distress, and depression.

2. An expanded stressor model. This model conceptualizes work and family conflict or family and work conflict as mediating components between work role conflict, work role ambiguity, work time demands, job involvement, work satisfaction and family role conflict, family role ambiguity, family time demands, family involvement, family satisfaction (or live satisfaction).

3. A partial mediating stressor model. The following model refers to work and family conflict conceptualized as separate work and family conflict or family and work conflict constructs, i.e. work and family conflict or family and work conflict are mediating between work social support, work involvement, work role conflict, work time demands, work role ambiguity, family social support, family involvement, family role conflict, family time demands, family role ambiguity and job satisfaction and family satisfaction.

4. Integrative work-family conflict model. This work-family conflict model refers to the following elements: work antecedents (work social support, work involvement, work role conflict, work time demands, 
work role ambiguity), family antecedents (family social support, family involvement, family role conflict, family time demands, family role ambiguity), work outcomes (job satisfaction), family ourtcomes (family satisfaction) and life outcomes (life satisfaction).

Michel et al. (2009) indicates that, for instance, family time demands (hours worked, number of children and age of youngest child) rather fractionally effect family and work conflict. This is highly significant implication for employees experiencing family demands, here especially mentioning working mothers. According to the research data, one of the main factors affecting decisions being related to work and family conflict refers to the support provided for an employee by an organization and its executive. Needless to mention, work and family conflict is also tackled at state level by regulating application of flexible work management means. The second relevant result refers to the the relationship between social support and role conflict: work social support and work role conflict, and family social support and family role conflict (Michel et al., 2011). The research accomplished by Cesnaukas and Lazaskaité-Zabielskè (2009) revealed that perceived support of employer and job satisfaction are indeed relevant for making work and family conflict decisions. Yet, it is interesting that perceived organizational support and presence or absence of organizational family-friendly policy did not affect experienced work and family conflict at all. It was also determined that personal abilities to solve arising conflicts and problems both ways - work and family or family and work - prevents from high level conflict. The authors noticed that if one's believe being able to manage work and family responsibilities despite any difficulties, the work and family or family and work conflict level becomes lower. This indicates that all the decisions taken at individual level are the most effective and contributing to conflict prevention. It is also noted that is very important to consider the specific issues trying to solve them here and now. Greenhaus and Powell (2006) remarked as well the strong connection emphasizing social support or individual family member support and career success, career management, or satisfaction at work. Hill (2005) here referred to four dimentional model: Work-Family Conflict, Work-Family Fatilitation, Family-Work Conflict and Family-Work Fatilitation. Yet Wayne et al. (2004) emphasized that it is most relevant to consider three domains: Work-Family Conflict, Work-Family Fatilitation and the Role of Personality.

However, the conflict theory may also be out-weighted by work-family facilitation and family-work facilitation theory (Hill, 2005). Work-family facilitation and family-work facilitation theory suggests that certain skills, attitudes and experiences acquired at work may facilitate performance of family duties as well as those acquired at work may increase work performance in professional work. 
Ilona Tandzegolskienè, Elena Trepulè, Aušra Rutkienè, Giedrè Tamoliūnè, Vaida Jurgilè. A Model of Family and Career Reconciliation

The facilitation relationship between family and work was first indicated by Crouter (1984) who drew attention to the neglected side of work and family interface referring to positive side of the interaction. However, since 1980s the topic was not further developed until the late 1990s and further. According to Hill et al. (2007) that trend changed during the 2000s when there was a clear shift in focus toward work and family facilitation. According to Froneet et al. (2003) work-family facilitation is defined as the extent to which participation at work [or home] is made easier because of the experiences, skills, and opportunities gained or developed at home [or work]. In the study of Hill et al. (2007) employees of a large multinational corporation (IBM) were asked to describe the positive influences of their work life on their home life and vice versa. Work place flexibility, financial benefits, and the ability to keep family commitments were most often mentioned by the participants as important components of work-to-home facilitation, whereas supportive family relationships, psychological benefits of home, and psychological aspects of work were most frequently named as important components of family-to-work facilitation. As conflict theory is offering a sobering attitude to the reality of conflicting requirements that work and family raise to a working parent, whereas, facilitation theory is offering an idea of a constructive dialogue to reconcile work and family requirements of working parents.

Concluding other authors' researches Wayne et al. (2004) noticed that usually role conflicts occur when too many requirements are placed on one's limited time, stress and strain. The conflicts usually arise when (a) the roles experience time pressure therefore it becomes complicated for one role to comply with the expectations from the other role"or produce a preoccupation with one role while physically attempting to fulfill the other role", (b) stress in one domain can cause tension, fatigue, and irritability which can have influence to one's performance in the other domain, or (c) the behaviors which are used in one role are incongruous with the behaviors required in the other role Wayne et al. (2004:110). This conflict is bidirectional and affects both domains: work role from one side and family role form the other. Theoretically the individual who is performing both family and employee roles and is experiencing the role conflict is forced to use the time more efficiently, to perform the roles with more energy and less stress or to be able to adopt or copy stress reduction strategies.In the face of the analyzed three strains of conflict, facilitation and roles the dynamics of families dealing with career and family reconciliation situations, families are also effected by a set of internal and external factors that model and career dimension the intensity of their situations. 


\section{Empirical research results' influence on the model development}

The planned research covers several stages, namely, (1) the analysis of literature, (2) the interview with young families, employers and career guidance/HR specialists, (3) the questionnaire-survey for young families, and (4) preparation of work-young family reconciliation model. Below are presented certain characteristics of three qualitative research cases and quantitative research accomplished during the second stage:

1. 15 narrative-interviews with young families (both parents mother and father) were implemented in January-April 2015. Research participants were selected according to the following criterions: parents under age of 35; a family has a child/children under age of 12; both partners have experience in the professional realm, i.e., have already worked before having children. In the narrative interviews the following sequence of life stages has been followed: child birth -> maternity/paternity leave (1-2 years) $->$ mother's/father's return to work -> child's entry to kindergarten -> child's entry to school.

2. $\quad 14$ semi-structured interviews with employers from private and public sectors in different counties were implemented in February-April 2015. The target group was created by applying targeted selection method in non-probability sampling. The semi-structured interview instruments were focused on the following topics: a) creation of family-friendly work place; b) necessity for flexible work schedule; c) development of decrees regulating support in respect to the needs of young parents.

3. The focus group of 6 experts in career counseling was organized in September, 2015. The experts were selected according to their compliance to the goals of the research. Questions for experts in focus group covered topics about career guides' and Human resource (HR) specialists' experience with young parents looking for a job or seeking guidance, how they support such employees or candidates in terms of information provision or career guidance, how they collect information about the family status and needs and also career guides/HR specialists were asked to comment on the existing legislation and state provisions for young families with children in employment.

4. The quantitative research participants were representing all the municipalities of Lithuania mainly referring to mothers who were raising up to 12 years age children ( 350 or 88,4 percent), fathers -44 (or 11,1 percent) and 2 foster carers. The majority of the respondents indicated having higher education background $-67,4$ percent $(267$ 
Ilona Tandzegolskienè, Elena Trepulè, Aušra Rutkienè, Giedrè Tamoliūnè, Vaida Jurgilè. A Model of Family and Career Reconciliation

respondents), non-university higher education (applied sciences) 25,3 percent (100 respondents), occupational or secondary education 7,3 percent (29 respondents). The research was based on the questionnaire survey method. The questionnaire was prepared according to the theoretical model being set up by the group of the researchers (Tandzegolskiene et al., 2014) referring to the accomplished narrative analysis of young families and employers" insights, as well as focus group (career specialists and human resources managers) generalizations (Tandzegolskiene et al., 2014). The online survey was accomplished in March-May, 2016.

\section{Findings}

Narratives' perspective:This phenomenon (roles of personality) is especially significant after the birth of first child, although parents who have more than one child shared experiences on stronger lack of 'Myself' as most of the time and energy, apart from work, is spent for arranging family duties, logistics issues, distributing roles among family members, etc. This change is extremely difficult at the moment when mother and/or father decides to return to work after maternity/paternity leave because this moment is not just about the decision of who will take care of the baby but as well, what are the possibilities for changing career, seeking for better position, working full time or even workload. It is important to note that research participants represented dual career couples mainly, research results have revealed that these couples are more open for continuous dialogue, search for compromises and for extended family support perceiving these factors as a must for all life fields: family welfare, work and career as well as managing positive changes. Young parents emphasized that employers who are parents themselves, regardless from age of their children, are more open to search for flexible solutions and compromises when there is a need and especially when they see that young parent-employee is trying to achieve best results while being at work.

The Thematic analysis of the study is to present four main themes:

- Changing family model: Role reconciliation; Experience of internal conflicts; Search for compromises;

- Change management: Returning to the labour market; Setting priorities; Planning of financial and time resources; Search for work and family balance;

- Career management: Different types of career; Expedient career planning; Searching for intrinsic „Me“; Career development decisionmaking; 
- Supportive environment: State support; Organisation's nature and inner culture; Comparison of work and family skills; Family relations ${ }^{6}$ harmony.

The narrative interviews with young families where both partners (mother and father) were involved have distinguished that there is a big change in family models as nowadays most of parents feel more pressure to contribute actively to family welfare and child care and this implies bigger stress because of the transformation from "Me" to "Father" or "Mother". The time pressure is related with different roles being constantly applied at the same time adjusting own and children needs. However, the research analysis where both partners were participating in the interview highlighted the need and importance of continuous dialogue between parents about diverse roles they play, though unfortunately this appeared to be quite a challenging issue.

Employers' perspective: Employers are open for dialogue, discussions and search for new possibilities in the process of reconciliation. Even though sometimes there are strict rules or situations when employer must implement his/her duties and cannot leave the work place, research participants have expressed willingness and initiative in organizing consultations for employees on how to balance between parenthood duties and liabilities at work. As another factor enabling facilitation of duties at work and family, according to research participants could be organization of workshop, where different solutions could be discussed and analyzed in order to find adjustment for the needs of young parents who return to work after maternity/paternity leave. Apart from various activities implemented by employers, internal structural and organizational decisions and organizational legal aspects are equally important. As far as employers are reasonable and aware of employees with small children who may expect more flexible working environment, various alternations and solutions can be found.

To create main themes of this research are:

- Creation of young family-friendly workplace: Setting up of flexible work schedule; Providing engaging working conditions; Maintaining active employee-employer dialogue; Fostering social relations in organization; Influence of employment specifics; Workplace adjustments to young families' needs;

- Definition of formally regulated young family support: Formalisation of common agreements; Effectiveness of information provided by Personnel Department /Administration; The level of determining young parents' legal status;

- Employer's options to adjust to the various forms of support: Employer's possibilities to establish child-friendly environment; 
Ilona Tandzegolskienè, Elena Trepulè, Aušra Rutkienè, Giedrè Tamoliūnè, Vaida Jurgilè. A Model of Family and Career Reconciliation

Influence of organization's internal culture; Anticipating career development opportunities.

When discussing about help that employers need in order to improve quality of the service and support for young families who search for harmonization in this process, employers expressed the potential need for external support from experts by inviting them for consultations or even creating new work places so that the whole system would be created and assured in order to help young parents to accommodate new experiences, potential temporary challenges or difficulties through the transitional period. In this case, it is very important to discuss about parenthood-career reconciliation, management of organization and internal organizational support system.

Career counsellors' perspective: Career counsellors are expected to be ones who actively participate in the process of balance between family and career search as facilitators. Focus group discussion with experts in career counselling pointed out that there are several main issues when considering this specific problem. Firstly, many employees do not even know that there are professionals who could help in this precise situation, when help is needed in order to find a balance. Secondly, it is very often that young parents do not know updates of state legislation where the question of family and career is discussed as well as updates of job market strategies. This is especially to be said about legislation related to looking for a new job, interviewing with potential employers, etc. Apart from this, various other factors have been distinguished after the text analysis.

Categorization of career counsellors' and human resource specialists' approach to facilitation of family and work reconciliation:

- $\quad$ Pressure experienced by employees with small children;

- Development of career counselling services;

- Recommendations provided by career counsellors to employees;

- Keeping a consistent system/order determining child-care support during maternity/paternity leave and later.

Experts provide information that some young parents might not be aware of their rights not to answer questions related to family status during job interviews, as it is only competences that should be evaluated. According to career counsellors candidates should be prepared to positively answer questions about children, demonstrate their trust in themselves and abilities to manage situation, plan time, communicate with employer giving no opportunities for discrimination. Although employees/candidates must know and be confident that it is optional to disclose their personal information related to family status and children. 
Career counsellors confirmed fears expressed by parents that employers are not willing to employ young people who are planning to have a baby or already have one. Even though employers say that competency at workplace is more important than family status, it can be seen that this attitude might still demonstrate the lack of family friendly culture on all levels, i.e. personal, institutional and national. Nevertheless, the importance of personal need identification was clearly pointed out by all research participants: parents distinguished it as a tool buffering potential internal family conflict, employers see this as an easier way for employee to stand up for his needs, especially when decisions have to be made, and, finally, career counsellors point out that this identification must be made while children are small and at the most vulnerable.

Quantitative research perspective: The analysis of work-family conflict was accomplished following the six positions presented in the work-family model. Evaluation of each conflict contained the conceivable scale from 1 till 5 when 1 was the weakest and 5 - the strongest conflict expression. The research results revealed the evaluation of all conflict types as mean. The biggest conflict was experienced by the respondents while managing the time (family time management problems were transferred to work environment, and the lack of time provided for the family was detected). The stress was also initiated by the tension felt within the family and being transferred to working environment.

The analysis of work-family conflicts which influence each other was based on Spearman correlation indicating the strongest time management and tension conflicts' links which were transferred from working into family environment when the conflict initiated at work and transferred to home environment brought stronger tension and referred to the time management. Strong correlation was detected while evaluating conflict initiated by behaviour which was transferred from home into working environment and vice versa. That means, the conflicts being influenced by personal behaviours were stronger despite the causes' which might be attributed to work or home settings.

Referring to the analysis which tries to identify conceivable influence of family children quantity to the diverse elements of work-family conflict, the families were divided into three groups: those raising one child, two and three or more children. Applying the variance method (ANOVA) it was identified that only one conflict attribution may refer to the quantity of children a family raises - this is the tension being transferred from family into working environment. As it was stated formerly by the scientific researchers (Ahmad 2008; Malone, 2011; Anafartal \& Kuruüzüml, 2012; Mjoli et al., 2013), the research results just confirm - growing number of children within a family progressively increases the conflict: the mean evaluation of conflict for the families raising one child refers to 3,12 , two children $-3,34$, three and more children $-3,45\left(\mathrm{~F}=3,122, \mathrm{df}_{1}=2, \mathrm{df}_{2}=392, \mathrm{p}=0,045\right)$. In other cases covering the 
Ilona Tandzegolskienè, Elena Trepulè, Aušra Rutkienè, Giedrè Tamoliūnè, Vaida Jurgilè. A Model of Family and Career Reconciliation

diverse conflict tendencies, the distinctions were not statistically significant, though the means imply that during time management and tension conflict the higher quantity of children within the family usually increase the tension, meanwhile the tension is decreased in behaviour conflict. This might be explained by the fact that a bigger number of children within a family require higher behaviour flexibility, therefore the conflict level when flexibility is present noticeably decreases.

The summary implies that family conflicts are substantially transferred to professional field indicating high conflict tendency. Meanwhile, the conflicts referring to the opposite tendencies and addressing work-family environment are transferred less frequently. The quantity of children is one of the main and relevant factors influencing the conflicts' emergence. This is based by the research results revealing the tendencies of conflict being transferred from the family to working environment when depending on the quantity of family children. Another fact was exposed that parents appreciate more positively the situation covering family needs and pace of life, as well as working nature and occupational commitments when family life and occupational activity do not interfere and enable to perform obligations in both fields at the same time experiencing less conflict situations. Conflicts based on the behaviour issues are not basically influenced by the parents' positive disposition. Thus, the behaviour is influenced by income which affects the exceeding conflict while increasing.

\section{Common research results' dispute and model presentation}

Discussing young family career and parenthood reconsiliation possibilities the relevance of family conception comes first, as well as reconsiliation of family needs and diverse problematic situations referring to working activities and obligations. Career conception and development of career management skills are also relevant discussing work and family reconciliation opportunities. Family seeking to reconciliateits needs refers to the positive parenthood development evaluating employment tendencies and career opportunities. Here certain barriers occur which are common while seeking for satisfaction in family and work reconciliation or developing career opportunities. What is important for reconciliation of young family parenthood and career is family attitude towards career when family is determined as dual career couple devoting sufficiently attention and energy for own career development. Family may also be determined as one career couple when only one family member seeks for the set career goals, meanwhile other family member is satisfied with present working place and does not seek for career or suspends career plans. The results of young families' narratives, as well as questionnaire analysis indicate that career development is usually prescribed for man, meanwhile woman upholds 
family (parental leave statistics: maternity leave $-84,6$ percent, paternity leave 3,8 percent, both partners leave $-11,6$ percent). It is also noticed that families usually apply one career couple model.

Chosen career model (see Figure 1) influences the dispute on three diverse situations - conflict intensity and tendency referring to work-family and familywork conflict (Higgins \& Duxbury, 1992; Carlson et al., 2000; Froneet al., 2003; Ahmad, 2008), role management difficulties and potential solutions (Milkie \& Peltola, 1999; Carlson \& Kacmar, 2002; Elloy \& Smith, 2003; Wayne et al., 2004; Moshin et al., 2013; Cesnauskas \& Lazauskaite-Zabielske, 2014) and facilitation of management of work-family reconciliation strategies (Crouter, 1984; Frone et al., 2003; Hill, 2005; Wayne et al., 2004; Hill et al., 2007). It is also relevant to discuss parents'obligations for family, as well as parenthood conception as such referring to role fulfillment and family responsibilities. Thus, the model construct distinguishes both internal and external factors which are relevant for reconciliation of family, parenthood and career. External factors refer to state level, social level and institutional (organization) level, meanwhile internal factors refer to the cycle of family life, quantity of children, age of children, children care, distribution of activities within a family, support of relatives. Both external and internal factors are related to emerging conflicts (work-family or family-work, role conflict) and possible solutions which are backed up by facilitation strategies and acquired work-family reconciliation management skills.

Theoretical analysis of external and internal factors indicates provided support and means which are presented as common indivisible totality, in each case, depending on a situation while searching for compromise or solution covering social and institutional level, and referring to legislative framework. Political documents might contribute in order to perceive the process of social support as diverse social advantages refer to regulated documents. Familty narratives revealed that it is important for young family to survive and solve existing tensions and conflicts related to both family and work environments. Questionnaire analysis of young parents confirms this attitude and shows that conflicts and problems originating within a family are more relevant than those originating within work settings. Most common conflict causes are related to time management and tension when work and family pace is not balanced.

Presentation of roles that young parents assume reveals discussions about transformation and new level of role perception. Young families seek for supportive dialogue and relation harmony while being together. Here the conception of positive parenthood might be highlighted including aim to recon ciliate diverse roles taking certain responsibility: becoming a mother/a father, being a spouse, corresponding to the conception of a good employee, etc. 
Ilona Tandzegolskienè, Elena Trepulè, Aušra Rutkienè, Giedrè Tamoliūnè, Vaida Jurgilè. A Model of Family and Career Reconciliation

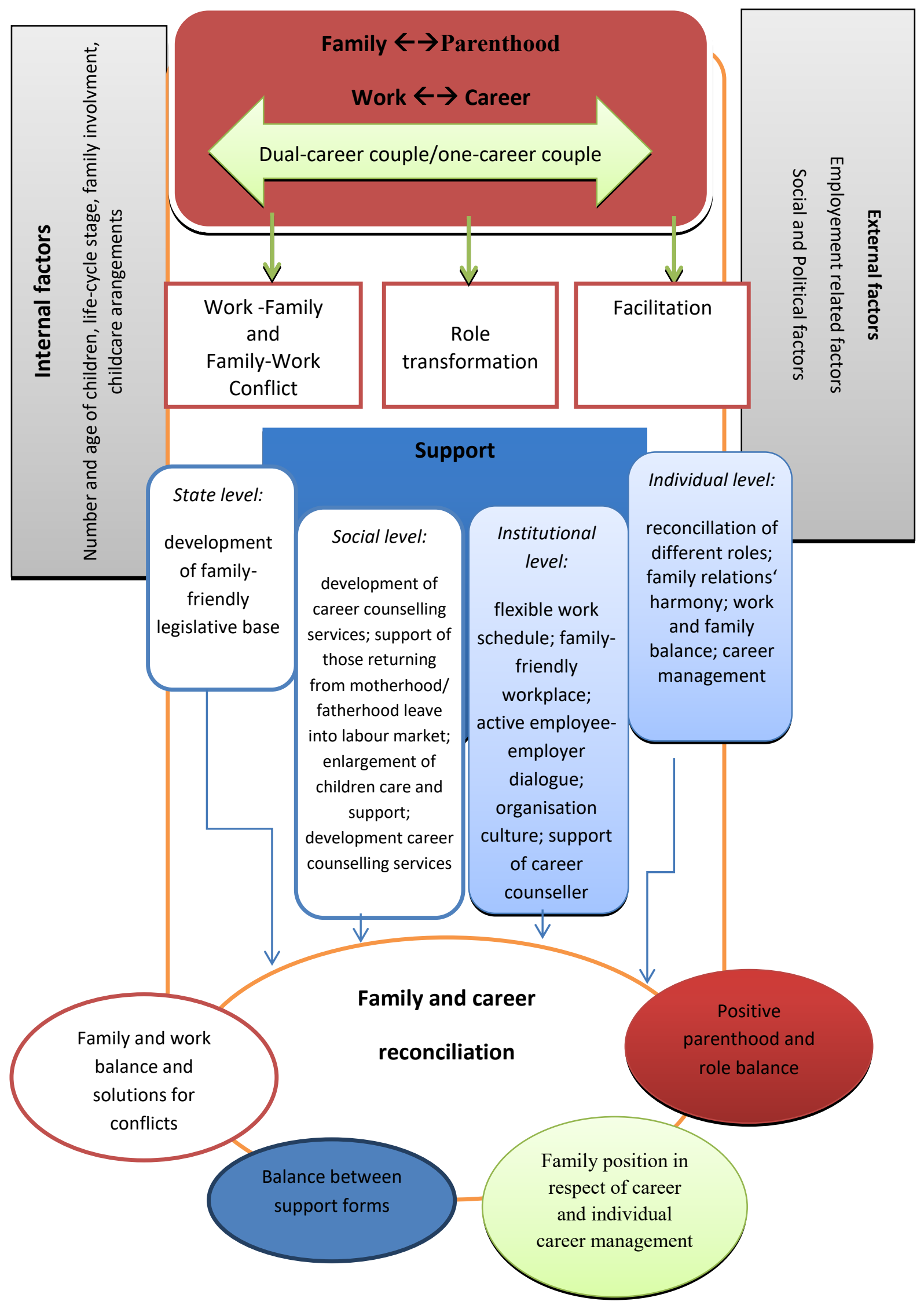

Figure 1 Family and career reconciliation model 
Analysis of research results revealed that while talking about the support, the social one, institutional and individual support were emphasized when family members are searching for solutions themselves trying to help each other. It is also noticed that parents wish to have different support and this is related to economic factors: disbursements, exemption system, after-class activities at no charge, inexpensive non-formal learning services. Prevision of career goals or career planning are more related to family needs and plans, or partly related to employer's offers and work peculiarities. Employers' interview revealed that is relevant to talk about setting up a worker-friendly place especially for those workers having young children, as flexible working conditions, timetable, dialogue with an employer, possibility to bring a child/children to an equiped working place, or take an advantage of career counselors' and human resource manager's services about career planning are very important. All this may refer to the development of employee-friendly organization culture. Interview with the experts confirms the need to pay attention to the problems young families experience while trying to reconciliate work and family, therefore career counselling system should be developed on both institutional and state levels.

The results of questionnaire analysis indicate that the internet and social media serve as the basic source of information about rights and support offers for those parents who raise children. Young parents state that they are acquinted with the legislative framework providing family exemptions in relation to family and work reconciliation.

Analysis of scientific literature and accomplished research reports lead to the statement that family and work reconciliation refers to four main contexts: family and work reconciliation and solving conflicts, compatibility of diverse support forms, family attitude towards career and individual career planning, as well as positive parenthood and responsible role coordination

\section{Conclusions}

The analysis of parents opportunities for family and career reconciliation revealed several tendencies highlighting strong conflict between work and family or family and work balance what is accompanied by role conflict and ability to transfer existing knowledge and skills from family to work sphere or from work to family sphere trying to cope with all the difficulties and problems. In most cases, conflicts appear due to dissatisfaction with the present work or experiencing family pressure when the needs, time and strength resources of family members are considered. The age of children does also influence reconsiliation, namely, if children are very young, reconsiliation of career, work and family needs becomes more difficult. The role conflict is also noticeable when accepted or assigned roles demand much time expenditures or 
Ilona Tandzegolskienè, Elena Trepulè, Aušra Rutkienè, Giedrè Tamoliūnè, Vaida Jurgilè. A Model of Family and Career Reconciliation

empowerment as this subtracts a lot of energy and leads towards dissatisfaction with working activities, career progress or planned family life stages. Family support may refer to several dimensions covering state, social support, institutional or individual levels. Each support level is significant and prerequisite, however, the strongest factors are considered to be institutional and individual levels. Employer support and understanding, as well as support provided by a spouse or relatives are given the main emphasis. Career conception has been analyzed within a family as dual career system or individual, one couple career system. However, career analysis attains less attention, as the aspects of professional dimension and professional empowerment have been highlighted while covering present work satisfaction, ability to manage assigned roles within working environment, setting up employee-friendly workplace, providing flexible working schedule, and child/children support.

\section{Acknowledgement}

The financial support provided by the Research Council of Lithuania for the research and proof-reading of English language is gratefully acknowledged (Project Reg. No. MIP-075/2014). The article translated by Dr. Eilina Dailidienè.

\section{References}

Ahmad, A. (2008). Job, Family and Individual Factors as Predictors of Work-Family Conflict. The Journal of Human Resource and Adult Learning, 4 (1). 57-65.

Anafartal, N., \& Kuruüzüml, A. (2012). Demographic Predictors of Work-Family Conflict for Men and Women: Turkish Case. International Journal of Business and Management. Vol. 7 No. 13. 145-158.

Carlson, D. S., \& Kacmar, K. M. (2002). Work family conflict in the organization: Do life role values make a difference? Journal of Management, 26 (5). 1031-1054.

Carlson, S. D., Kacmar, K. M., \& Williams, L. J. (2000).Construction and Initial Validation of a Multidimensional Measure of Work-Family Conflict. Journal of Vocational Behavior, 56 (2). 249-276.

Cesnauskas, V., \& Lazauskaite-Zabielske, J. (2014). Darbo ir šeimos konfliktas: individualiu ir organizaciniu veiksniu svarba. Organizaciju vadyba: sisteminiai tyrimai. Kaunas: Vytauto Didžiojo universitetas, 72. 23-43.

Coser, L. A. (1974). Greedy Institutions. Patterns of Undivided Commitment. The Free Press: New York.

Crouter, A. C. (1984). Spillover from family to work: The neglected side of the workfamily interface. Human Relations. 37 (6). 425-442.

Elloy, D., \& Fand Smith, C. R. (2003). Patterns of Stress, Work-Family Conflict, Role Conflict, Role Ambiguity and Overload Among Dual-Career and Single-Career 
Couples: An Australian Study. Cross Cultural Management: An International Journa, 10 (1). $55-66$.

Frone, M., Russell, M., \& Barnes, G. (2003).Work-family balance. In J. Quick \& L. Tetrick (Eds.), Handbook of occupational psychology. Washington: American Psychological Association. 143-162.

Greenhaus, J., \& Powell, G. (2006). When work and family are allies: a theory of workfamily enrichment.Academy of Management Review, 1. 72-92.

Higgins, C. A., \& Duxbury, L. E. (1992). Work-Family Conflict: A Comparison of DualCareer and Traditional-Career Men. Journal of Organizational Behavior. John Wiley \& Sons, 13 (4). 389-411.

Hill, E., J. (2005). Work-Family Facilitation and Conflict, Working Fathers and Mothers, Work-Family Stressors and Support. Journal of Family Issues, 26. 793-819.

Hill, E. J., Allen, S., Jacob, Bair, A. F., Bikhazi, S. L., Van Langeveld, A., Martinengo, G., Parker, T. T., \& Walker, E. (2007). Work-Family Facilitation: Expanding Theoretical Understanding Through Qualitative Exploration. Advances in Developing Human Resources, 9 (4). 507-526.

Kempe, J., \& Otonkorpi-Lehtoranta, K. (2006). Family-friendly personnel policy and workp lace culture-challenges for working life. Posibilites and challenges mens reconciliation of work and family life. Conference report. Nord ic Council of Ministers, Copenhagen.

Malone, K. A. (2011). Mother's perceptions of work-family conflict and the relationship to positive parenting, and parental satisfaction'. $\mathrm{PhD}$ dissertation, Ames, Iowa.

Michel, J. S., Mitchelson, J. K., Kotrba, L. M., LeBreton, J. M., \& Baltes, B. B. (2009). A comparative test of work-family conflict models and critical examination of workfamily linkages. Journal of Vocational Behavior, 74 (2). 199-218.

Michel, J. S., Kotrba, L. M., Mitchelson, J. K., Clark, M. A., \& Baltes, B. B. (2011). Antecedents of Work-family Conflict: A Meta-Analitic Review. Journal of Organizational Behavior, 32. 689-725.

Milkie, M. A., \& Peltola, P. (1999). Playing All the Roles: Gender the Work-Family Balancing Act. Journal of Marriage and the Family, 61 (2). 476-490.

Mjoli, T., Dywili, M., \& Dodd, N. (2013). Demographic Determinants of Work - Family Conflict among Female actory Workers in South Africa. Journal of Economics, Business and Management, 1 (1). 30-41.

Moen, P. (2003). It's about Time: Couples and Careers. ILR Press Books.

Moshin, A., Adnan, A., Sultan, Sh., \& Sabira, Sh. (2013). Role of trust in marital satisfaction among single and dual-career couples. International Journal of Research Studies in Psychology, 2(4). 53-62.

Parasuraman, S., \& Greenhouse, J. H. (2002). Toward reducing some critical gaps in workfamily research.Human Resource Management Review, 12. 299-312.

Tandzegolskiene, I., Rutkiene, A., Trepule, E., Tamoliune, G., \& Jurgile, V. (2016). Facilitating work and family conflict: young family case. Europan Scientific Journal July 2016 /SPECIAL/edition. 208-216.

Thurairajah, K. (2013). Work Family Conflict and its impact on Career and relation to Gender. European Journal of Business and Management, 5 (30). 1-12.

Vuga, J., \& Juvan, J. (2013). Work-family conflict between two greedy institutions - the family and the military.Current Sociology, 61 (7). 1058-1077.

Wayne, H. J., Musisca, N., \& Fleeson, W. (2004). Considering the role of personality in the work-family experience: Relationship of the big five to work-family conflict and facilitation. Journal of Vovational Behavior, 64. 108-130. 